\title{
Polycomb repressor complex 2 function in breast cancer (Review)
}

\author{
COURTNEY J. MARTIN and ROGER A. MOOREHEAD
}

Department of Biomedical Sciences, Ontario Veterinary College, University of Guelph, Guelph, ON N1G2W1, Canada

Received July 10, 2020; Accepted September 7, 2020

DOI: $10.3892 /$ ijo.2020.5122

\begin{abstract}
Epigenetic modifications are important contributors to the regulation of genes within the chromatin. The polycomb repressive complex 2 (PRC2) is a multi-subunit protein complex that is involved in silencing gene expression through the trimethylation of lysine 27 at histone 3 (H3K27me3). The dysregulation of this modification has been associated with tumorigenicity through the increased repression of tumour suppressor genes via condensing DNA to reduce access to the transcription start site (TSS) within tumor suppressor gene promoters. In the present review, the core proteins of PRC2, as well as key accessory proteins, will be described. In addition, mechanisms controlling the recruitment of the PRC2 complex to H3K27 will be outlined. Finally, literature identifying the role of PRC2 in breast cancer proliferation, apoptosis and migration, including the potential roles of long non-coding RNAs and the miR-200 family will be summarized as will the potential use of the PRC2 complex as a therapeutic target.
\end{abstract}

\section{Contents}

1. Introduction

2. Polycomb repressive complex 2

3. PRC2 core subunits

4. PRC2 accessory proteins

5. Recruitment of PRC2

6. Effect of PRC2 on breast cancer

7. EZH2 has oncogenic properties independent of the PRC2 complex

8. Dysregulation of long non-coding RNAs alters PRC2 activity in cancer

9. The miR-200 family and PRC2 activity in breast cancer

10. Therapeutics targeting PRC2 activity in cancers

11. Conclusion

Correspondence to: Dr Roger A. Moorehead, Department of Biomedical Sciences, Ontario Veterinary College, University of Guelph, Guelph, ON N1G2W1, Canada

E-mail:rmoorehe@uoguelph.ca

Key words: polycomb repressor complex 2, breast cancer, H3K27me3, enhancer of zeste homolog 2, long non-coding RNA, miR-200

\section{Introduction}

Epigenetic modifications, including DNA methylation and histone modifications, play an important role in gene regulation. The dysregulation of these modifications can result in pathogenicity, including tumorigenicity. Research has indicated an important influence of the trimethylation modification at lysine 27 on histone H3 (H3K27me3) within chromatin. This methylation is involved in the repression of multiple genes within the genome by condensing DNA to reduce access to the transcription start site (TSS) within gene promoter sequences (1). The recruitment of H1.2, an $\mathrm{H} 1$ histone subtype, by the H3K27me3 modification has been a suggested as a mechanism for mediating this compaction (1). The present review discusses the function of the H3K27me3 regulator, polycomb repressive complex 2 (PRC2), and its contribution to cancer, specifically highlighting alterations in breast cancer.

\section{Polycomb repressive complex 2}

PRC2 is a multi-subunit protein complex that mediates the mono-, di and tri-methylation of H3K27 to silence gene expression (1-6). First established in Drosophila, the polycomb group (PcG) genes are well conserved across species through to human cells (7-10). The PRC2 complex contains 4 core subunits, including the enhancer of zeste homolog 1 or $2(\mathrm{EZH1/2)}$, embryonic ectoderm development (EED), suppressor of zeste 12 (SUZ12) and retinoblastoma associated protein 46/48, (RbAP46/48), also known as RBBP4/7 (Fig. 1) (9,11). This core complex can additionally interact with accessory proteins consisting of the jumonji, AT-rich interactive domain 2 (JARID2), AE binding protein 2 (AEBP2) and polycomb-like protein (PCL) (11-15). Together, these subunits can form a holo-PRC2 complex to efficiently methylate histone $\mathrm{H} 3$. In general, approximately $70 \%$ of $\mathrm{H} 3$ histones can be methylated by $\mathrm{PRC} 2$, indicating the main regulatory role PRC2 has within the genome (4).

\section{PRC2 core subunits}

Although there are 4 core subunits of PRC2, only SUZ12, EED and EZH2 are required for the basic function of this complex (16-18). Within the core complex, there are two functional lobes that govern catalytic and regulatory duties. The catalytic lobe consists of the VEFS domain in SUZ12 and the SANT1L/2L, CXC motif and suppressor of variegation, 
enhancer of zeste, trithorax (SET) domains all within the EZH2 subunit (19). The methyltransferase activity of PRC2 has been specifically linked to the SET domain of EZH2 $(2,3,5,20)$. By contrast, the regulatory lobe consists of the SR motif and SET activation loop domain (SAL) of the EED subunit (19). The SAL domain is required for catalytic function by playing a main role in the coordination of these two lobes $(19,21)$. The interactions between these domains allow EED to recognize the presence of the H3K27me3 modification through the WD40 domain and stimulate the methyltransferase activity produced through the EZH2 subunit $(17,22)$. Overall, the EED subunit is important for reading the modifications, SUZ12 is important for the stabilization of this interaction and EZH2 is the methyltransferase subunit. When individually isolated, these subunits do not have PRC2 methyltransferase activity, suggesting that these peptides have to cooperate to accomplish their functions $(18,23)$.

The interaction between EED and EZH2 is facilitated through the EED binding domain (EBD) of EZH2 (24). This interaction entails the formation of a $\beta$-propeller through a 7 WD40 repeat sequence on the EED subunit to establish Van der Waals interactions and hydrogen bonds with the EBD (24). EZH2 envelops EED through multiple associations, closely linking these subunits structurally and as a result, functionally. In general, methyltransferase activity is initiated by the EED WD40 domain reading the H3K27me3 modification to induce a rotational change of the PRC2 confirmation and signals to the EZH2 subunit to activate catalytic function (19). The knockdown of EED is associated with a global reduction in H3K27me3 levels (25).

The second subunit, SUZ12, is involved in the stabilization of the PRC2 complex during catalytic activity (26). This stabilizing action is considered to be specifically linked to the VEFS domain of SUZ12 (27). More detailed research is required for the full analysis of processes involved with this subunit; however, the overall importance of this subunit is upheld by the observation that the knockdown of SUZ12 is also associated with a global reduction in $\mathrm{H} 3 \mathrm{~K} 27 \mathrm{me} 3$ levels $(18,26)$.

The third subunit, EZH1/2, is considered the writer protein in which the catalytic function of PRC2 is carried out through. This peptide is a methyltransferase that adds a methyl group to lysine 27 on histone $\mathrm{H} 3$ through activity within the SET domain $(21,28)$. Both EZH1 and EZH2 have the capacity to form PRC2 complexes, but may not be completely interchangeable. EHZ2 has been observed to have a higher methyltransferase activity compared to EZH1 (29). For instance, EZH1 has been observed to specialize in only the mono- and di-methylation of H3K27, while EZH2 catalyzes mono-, di- and trimethylations (30). In addition to this complex, EZH2 may have PRC2-independent activity that will be discussed below in the present review.

Finally, some research considers RBBP4/7 part of the core subunits of PRC2, while others consider it as an accessory protein. In general, these peptides play a role in the stabilization and regulation of PRC2-chromatin interactions by binding the unmethylated histone H3K4 tail (31). This binding is impaired when $\mathrm{H} 3 \mathrm{~K} 4 \mathrm{me} 3$ is present, therefore indicating to the PRC2 complex that the gene is currently active $(31,32)$. Although only SUZ12, EED and EZH2 are required for any enzymatic activity, RBBP4/7 may be considered a core subunit due to the control it contributes to the complex $(18,23,33)$. Furthermore, RBBP4 and RBBP7 are part of the WD40 repeat protein family that acts to stabilize the PRC2-chromatin interaction. This occurs through the simultaneous binding of PRC2, $\mathrm{H} 3$ and $\mathrm{H} 4(31,34,35)$. The binding of $\mathrm{H} 4$ by RBBP4/7 causes a structural change to unfold helix 1 of $\mathrm{H} 4$ to support this process (34). Within the PRC2 complex, RBBP7 is closely associated with SUZ12, but only weakly to EED (16). Moreover, this incorporation into the PRC2 complex is SUZ12-dependent (16). Functionally, RBBP4 and RBBP7 are similar and have been studied closely together.

\section{PRC2 accessory proteins}

The accessory proteins interact with the core subunits ultimately to enhance PRC2 function by increasing stability, regulating catalytic function or aiding in the recruitment of the PRC2 complex to a locus. Accessory proteins that interact with the PRC2 complex include JARID2, AEBP2 and PCLs.

JARID2 contains 4 domains, 2 jumonji and 2 DNA binding $(14,36)$. This peptide occupies the same area of the chromatin as PRC2 with affinity to $90 \%$ of the previously mapped PcG genes, supporting the hypothesis that JARID2 is a PRC2 accessory protein $(15,33)$. Furthermore, the DNA binding domains contain zinc fingers that interact with nucleosomes to recruit and stabilize both polycomb complexes involved in epigenetic gene silencing, PRC1 and PRC2 $(14,33,37,38)$. JARID2 has also been observed to interact with mono-ubiquitinated H2A lysine 119, a modification established by PRC1, to allow PRC2 and PRC1 to crosstalk (39-41). This may be a mechanism supporting the interdependency of these two polycomb complexes during epigenetic gene repression. Moreover, JARID2 is considered a regulator of PRC2-mediated $\mathrm{H} 3 \mathrm{~K} 27 \mathrm{me} 3$ based on methylation levels already present (12). While JARID2 has been observed to recruit PRC2 to a locus, the jumonji domains act to inhibit methyltransferase activity $(15,42)$. This domain negatively regulates the catalytic function of PRC2 to act as a controller $(15,42)$. In general, JARID2 is not required for maintaining global H3K27 methylation; however, it assists this process.

Closely associated with JARID2 is AEBP2 (41). Together, these proteins stimulate PRC2 methyltransferase activity in a synergistic manner (38). AEBP2 has 2 isoforms, short and long, which are developmental stage-specific (13). The short isoform is associated with the embryo developmental stage, while the large isoform is associated with the adult stage (13). This is a zinc finger protein that interacts with both PRC2 and DNA, mediating PRC2 recruitment and stabilization (13). Target loci of AEBP2 have been mapped close to those of $\mathrm{PRC} 2$, suggesting that this is a targeting protein for PRC2 (13). In general, AEBP2 is required for optimal PRC2 function (16).

Finally, PCL is a group of peptides that contain Tudor domains that can bind H3K36me3 markers, known to increase PRC2 recruitment $(43,44)$. Recruitment processes will be discussed in detail in the following section. Overall, there are 3 mammalian PCLs important for PRC2 activity. These include PHF1, MTF2 and PHF19, also known as PCL1, PCL2 and PCL3, respectively $(12,45)$. They all contain Tudor domains, 


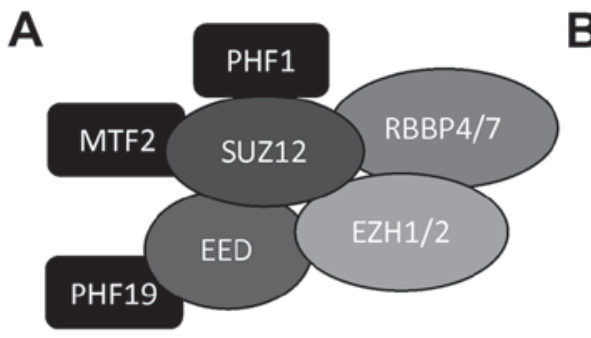

PRC2.1

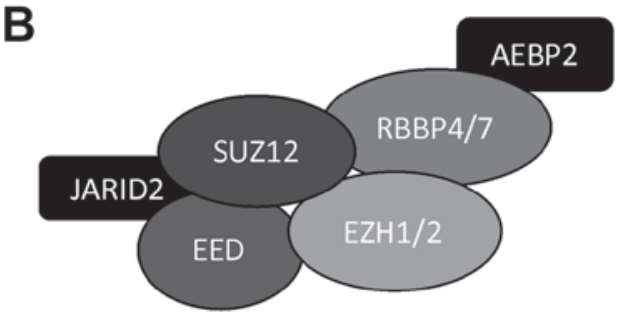

PRC2.2

Figure 1. (A and B) The PRC2 complex consists of 4 core subunits, including EZH1/2, EED, SUZ12 and retinoblastoma associated protein 46/48, (RbAP46/48 or RBBP4/7). RBBP4/7 is closely associated with SUZ12, but not with EED. In addition to the core subunits the PRC2 complex can include accessory proteins. (A) The PRC2.1 complex consists of the 4 core subunits and PCLs, including PHF1, MTF2 and PHF19, also known as PCL1, PCL2 and PCL3, respectively. (B) The PRC2.2 complex consists of the 4 PRC2 core subunits and the two accessory proteins, JARID2 and AEBP2. During recruitment, JARID2 specifically associates with the EED subunit. PRC2, polycomb repressive complex 2; EZH1/2, enhancer of zeste homolog 1 or 2; EED, embryonic ectoderm development; SUZ12, suppressor of zeste 12; PCLs, polycomb like-proteins; JARID2, jumonji, AT-rich interactive domain 2; AEBP2, AE binding protein 2.

2 plant homeodomain fingers, an extended homologous region $\mathrm{N}$ terminal cluster and $\mathrm{C}$ terminal Chromo-like domain (46). These proteins may be particularly associated with promoting new PcG modifications of genes not previously silenced. More recently, PHF20L1, another TUDOR domain containing protein has been identified as a $\mathrm{H} 3 \mathrm{~K} 27 \mathrm{me} 2$ reader that can recruit PRC2 (47).

The mapping of the PRC2 complex has revealed that these accessory proteins form 2 distinct complexes, identified as PRC2.1 and PRC2.2 (Fig. 1) (12). PRC2.1 was identified as containing PCLs as the accessory proteins, while PRC2.2 exclusively contained JARID2 and AEBP2 (Fig. 1) (12). Further analysis suggested that PRC2.1 was involved in the de novo recruitment of $\mathrm{PRC} 2$ to $\mathrm{CpG}$ islands that lack H3K27me3 $(46,48)$. By contrast, PRC2.2 has been suggested to be involved in methyltransferase activity through recruitment to chromatin that has PcG-dependent modifications, H3K119ub or H3K27me3, already present $(39,41)$.

\section{Recruitment of PRC2}

Once H3K27 is trimethylated, the histone must remain in this state to continue the repression of the gene at hand, avoiding improper transcription. When an $\mathrm{H} 3 \mathrm{~K} 27 \mathrm{me} 3$ is already present, PRC2 can be recruited to the chromatin, allowing EED to read the marker (Fig. 2A) $(22,49,50)$. A positive feedback loop can then be initiated to stimulate $\mathrm{PRC} 2$ methyltransferase activity. This activation can propagate the $\mathrm{H} 3 \mathrm{~K} 27 \mathrm{me} 2 / 3$ marker in cis and far cis through long-range contacts (50). In general, this method of recruitment is involved in the maintenance and propagation of $\mathrm{H} 3 \mathrm{~K} 27 \mathrm{me} 3$, although this is not the sole form of recruitment.

PRC1, another PcG complex, also plays a significant role during the recruitment of PRC2. PRC1 and PRC2 have an interdependent association where they can recruit one another. This is supported by the co-localization of PRC1 and PRC2 to approximately $10-15 \%$ of all genes (51-54). PRC1 is an ubiquitin ligase that can be recruited to $\mathrm{H} 3 \mathrm{~K} 27 \mathrm{me} 3$ by chromobox subunits (CBX), CBX7 and CBX8 $(55,56)$. Subsequently, $\mathrm{PRC} 1$ recruitment and activation initiate the ubiquitination of lysine 119 at histone 2A (H2AK119ub1) (40,41). As a result, the ubiquitination marker can recruit and activate $\mathrm{PRC} 2$, again spreading H3K27 trimethylation (Fig. 2B) (41,57,58). TRIM37 has also been observed to ubiquitinate H2AK119 (59). This protein binds both PRC1 and PRC2, specifically targeting genes for silencing (59). Although the mechanism of PRC2 recruitment by TRIM37 has not yet been fully established, the knockdown of TRIM37 induces the re-expression of silenced genes due to the dissociation of PRC1 and PRC2 from the target locus (59).

Overall, recruitment to sites with $\mathrm{H} 3 \mathrm{~K} 27 \mathrm{me} 3$ or H2AK119ub already present occurs through JARID2 $(39,41)$. This is largely a PRC1-dependent process in which JARID2 can dock on DNA by interacting with the H3K119ub modification $(39,41)$. JARID2 then catalytically stimulates the PRC2 complex through the methylation of JARID2 at lysine 116 (Fig. 2B) (60). The function of this modification is to allow JARID2 to bind EED at the WD40 domain, inducing a conformational change and leading to the increased catalytic activity of EZH2 (60). Additional interactions of other proteins within the holo-protein complex help stabilize the PRC2 interaction with the chromatin. This includes JARID2, AEBP2, RBBP4/7 with histone $\mathrm{H} 3$ or H4, EED and SUZ12.

Without $\mathrm{H} 3 \mathrm{~K} 27 \mathrm{me} 3$, the recruitment of PRC2 occurs through the presence of different accessory proteins. While PRC2.2, including JARID2 and AEBP2 can be recruited effectively through H3K27me3 or H2AK119ub markers, de novo recruitment appears to be limited to the PRC2.1 complex containing PCLs $(46,48)$. This recruitment appears to occur at $\mathrm{CpG}$ islands (CGI), an area of DNA that has a high frequency of cytosine and guanine (Fig. 2C) $(46,48)$. This area may have fewer nucleosomes; however, this observation is not a direct predictor of recruitment (61). More specifically, polycomb response elements (PREs) within these CGI are suggested to recruit PRC2 and PRC1 (62). These have been well characterized in Drosophila; however, identification and characterization within mammals have yet to be confirmed (63). More distinguished within mammalian cells is the de novo recruitment of PRC2 through the $\mathrm{H} 3 \mathrm{~K} 36 \mathrm{me} 3$ modification (Fig. 2C). H3K4me3 in combination with the H3K36me3 modification is associated with active genes (64). PRC2 may use the H3K36me3 modification to create balance within the chromatin, initiating the silencing of genes that were previously active. PCL proteins are specifically involved in this de novo recruitment. PHF19 can interact with H3K36me3 through its Tudor domain to create a contact 
A

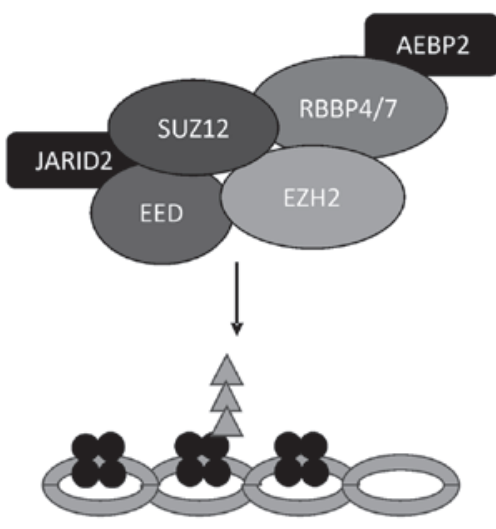

B

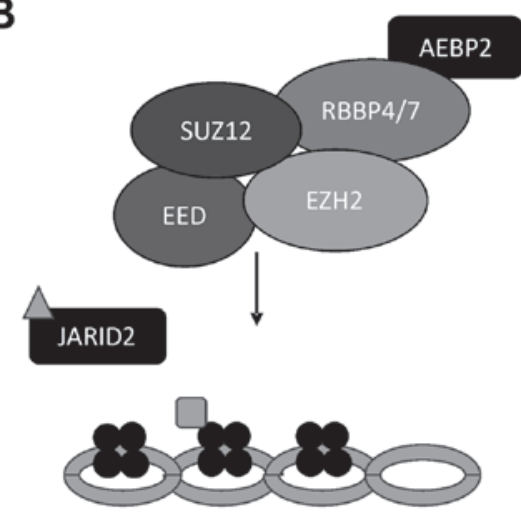

C
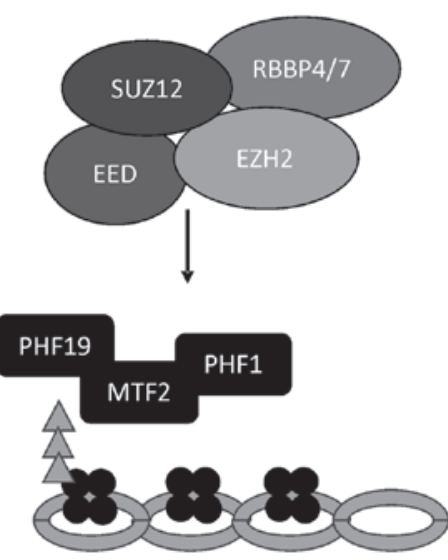

Figure 2. The possible mechanisms of recruiting the PRC2 complex to initiate the trimethylation of lysine 27 at histone H3 (H3K27me3). (A) PRC2 can be recruited to H3K27me3 (grey triangles) and recognized by the EED subunit. This activates EZH2 methyltransferase activity, creating a positive feedback-loop through EED to propagate H3K27me3 modifications within the chromatin. (B) PRC1-mediated ubiquitination (grey square) of lysine 119 at H2A (H2AK119ub) is recognized by JARID2 inducing methylation at lysine 116 (grey triangle). This methylation interacts with the WD40 domain on the EED subunit to initiate recruitment and methyltransferase activity. (C) Polycomb-independent recruitment occurs through PCL recognition of the trimethylation of lysine 36 on histone H3 (H3K36me3) at CpG islands. PHF19 can interact with H3K36me3 (grey triangles), while MTF2 and PHF1 can bind CpG islands to recruit PRC2 to the chromatin. PRC, polycomb repressive complex; EZH2 enhancer of zeste homolog 2; JARID2, jumonji, AT-rich interactive domain 2; EED, embryonic ectoderm development; SUZ12, suppressor of zeste 12.

point to recruit PRC2 (Fig. 2C) (43,65,66). Additionally, the demethylase, NO66, is recruited through PHF19 interactions with H3K36me3, overall resulting the gain of H3K27me3 and the loss of methylation at H3K36 by NO66 activity (65). MTF2 has also been observed to bind CGIs in the presence of $\mathrm{H} 3 \mathrm{~K} 36 \mathrm{me} 3$ and is an essential recruiter for PRC2 through de novo mechanisms in both mice and in vitro models $(46,48)$. Both MTF2 and PHF1 are observed to fold into a winged helix to successfully bind unmethylated $\mathrm{CpG}$ motifs (Fig. 2C) (46). Once PRC2 is successfully recruited, a positive feedback loop through the EED subunit sustains the methyltransferase activity at the CGIs to promote and propagate H3K27me3 (22).

Finally, long non-coding RNAs (lncRNAs) may additionally contribute to the recruitment of PRC2. A lncRNA termed HOX transcript antisense RNA (HOTAIR) has been identified to promote PRC2 binding in trans $(67,68)$. The HOTAIR-PRC2 mechanism seems to regulate specific genes, including HOXD10, PCDH10, PCDHBS, APC2 and $N L K(69,70)$. HOTAIR provides scaffolding for histone modification enzymes including PRC2 and LSD1, a lysine 4 demethylase (68). The binding of these enzymes occurs at the $5^{\prime}$ and $3^{\prime}$ ends of HOTAIR, respectively (68). Alterations to
HOTAIR levels have been observed in breast cancers, which will be addressed in detail below.

\section{Effect of PRC2 on breast cancer}

The altered regulation of genes is an important contributor to the pathogenicity of cancer. Since PRC2 alters epigenetic markers to repress genes, this complex may act to silence tumor suppressors, advancing tumorigenesis. Due to PRC2 targeting multiple genes, pin-pointing individual genes being silenced that directly contribute to cancer progression is a complex task. Some highlighted alterations in breast cancer that research has discovered are described below; however, it is unlikely this is the entirety of the effects of this complex.

PRC2 increases breast cancer cell proliferation. The proliferation of tumor cells is reduced when PRC2 subunits are knocked down, suggesting that this complex plays a role in breast tumor growth $(20,71)$. Specific genes linked to this process have yet to be identified within breast cancer cells, but are overall linked to $E Z H 2$ overexpression $(20,72,73)$. The levels of positive regulators of the cell cycle, including cyclinD1, cyclinE1, cyclinA2 and cyclinB1 are significantly 
reduced in cells that lack $E Z H 2$ expression (71). EZH2, as well as EED and SUZ12 are downstream targets of the pRB-E2F pathway, in that E2F can regulate the expression of these PCR2 subunits (71). Additionally, EED has also been identified as critical for proliferation, as the inhibition of EED-EZH2 interaction impairs tumor cell proliferation, thus providing further evidence that PRC2 activity facilitates proliferation (71,74).

PRC2 increases breast cancer cell invasion and metastasis. Metastatic breast cancer cells within adjacent lymph nodes have been shown to overexpress PRC2, which could suggest cells have acquired this alteration to gain the capacity to successfully metastasize (75). Within the primary tumor, matrix metallopeptidases (MMPs) play a key role in the degradation of the extracellular matrix (ECM) in the tumor microenvironment (TME) (76). The degradation of the ECM results in a higher frequency of the invasion and metastasis of breast cancer (77). Elevated EZH2 levels are associated with the repression of tissue inhibitors metalloproteinases (TIMPs) in triple-negative breast cancer (TNBC) (78). Specifically, EZH2 represses TIMP expression through the induction of the H3K27me3 silencing modification (78). Without TIMP proteins, MMP2 and MMP9 activity is increased, thus potentiating the metastatic capacity of breast cancer cells (78). This has also been observed in other types of cancer, such as ovarian and prostate cancer $(79,80)$.

Another potential target of the PRC2 complex that affects metastatic potential is the repression of growth differentiation factor-15 (GDF15) (81). Yes-associated protein (YAP) is an upstream regulator of the $\mathrm{PRC} 2$ complex that promotes trimethylation of $\mathrm{H} 3 \mathrm{~K} 27$ at the GDF15 promoter, leading to the suppression of GDF15 (81). When YAP is knocked down, the metastatic potential is decreased, suggesting that this recruitment of PRC2 to GDF15 may affect the aggressiveness of breast cancer cells (81). YAP expression and its role in breast cancers have been controversial with some research indicating a tumor-suppressive role, while others suggesting an oncogenic role (81-84).

PRC2 decreases apoptosis. Compounds that suppress PRC2 activity, such as 3-deazaneplanocin A (DZNeP), have been observed to re-induce apoptosis, leading to targeted cell death (85). F-box protein 32 (FBXO32) has been identified as a key effector of apoptosis in this process (85). Due to this re-expression, it can be suggested that during abnormal PRC2 activity, apoptosis is suppressed by reducing FBXO32 levels. Further support for a role of $\mathrm{PRC} 2$ in apoptosis includes the observation that elevated levels of EZH2 are associated with reduced apoptosis following DNA damage, while decreased levels of EZH2 potentially facilitate apoptosis (86-89). Mechanistically, FBXO32 is repressed by EZH2 (86). FBXO32 normally directly binds p21 for protease degradation within p53-proficient cells and additionally induces apoptosis in p53-deficient cells through CHK1 activation (86). When EZH2 is depleted, G1 and G2/M checkpoints of the cell cycle are inhibited, leading to the initiation of apoptosis with or without p53 involvement (86).

Another suggested pathway for evading apoptosis involves the deregulation of the $\mathrm{pRB} / \mathrm{E} 2 \mathrm{~F}$ pathway. When EZH2 is activated by E2F1, E2F1-mediated apoptosis is suppressed (87). This regulation of EZH2 leads to methyltransferase activity at the promoter of BIMI to induce the trimethylation of
H3K27, and furthermore, to suppress BIM1 expression (87). This process, induced by the $\mathrm{pRB} / \mathrm{E} 2 \mathrm{~F}$ pathway, suggests that suppressing $B I M 1$ is a potential alteration that occurs in cancer cells to escape apoptosis through epigenetic regulations. Within clinical cases, a high EZH2 expression is associated with a poor outcome, while $B M I 1$ overexpression is associated with good outcomes (90).

PRC2 induces epithelial-to-mesenchymal transition (EMT). An indication of EMT is the loss of E-cadherin $(\mathrm{CDHI})$ expression, a cell-to-cell adhesion molecule present in epithelial cells (91). The downregulation of $\mathrm{CDH1}$ is associated with increased invasiveness and progression in breast cancer (91-93). The repression of $\mathrm{CDH1}$ has been suggested to occur through the H3K27me3 marker created by the PRC2 complex (94). SNAI1 is associated with the increased binding of PRC2 to the promoter of $C D H 1$, leading to increased metastasis, invasion and EMT (94). SNAII can be regulated by the microRNA (miRNA/miR)-200 family to induce this PRC2 recruitment. This will be addressed in further detail below.

\section{EZH2 has oncogenic properties independent of the PRC2 complex}

Although EZH2 is a core PRC2 protein, it may also function independent of the PRC2 complex $(95,96)$. It has been suggested that EZH2 forms an additional complex with foxhead box M1 (FOXM1) under hypoxic conditions (97). Hypoxia-inducible factor 1-alpha (HIF1A) induces EZH2 expression, but suppresses $S U Z 12$ and EED expression and this scenario of elevated EZH2 protein levels in the absence of SUZ12 and EED promotes EZH2-FOXM1 interaction, resulting in the elevated expression of MMPs and increases tumor invasion (97). With this in mind, research that aims to address the effects of the PRC2 complex on cancer progression cannot solely measure EZH2 activity and increased H3K27me3 levels should be measured to confirm PRC2 activity.

\section{Dysregulation of long non-coding RNAs alters PRC2 activity in cancer}

lncRNAs have been emphasized more recently as regulators of PRC2 activity. The long non-coding RNA termed HOTAIR has been observed to promote PRC2 binding by acting as a scaffold (68). The dysregulation of this lncRNA has been observed during the progression of breast cancer and is associated with poorer clinical outcomes $(98,99)$. Particularly, the increased expression of HOTAIR is observed in primary breast cancers and metastases, and predicts the detachment of tumor cells, potentially leading to metastasis (69). By contrast, the knockdown of HOTAIR represses migration, invasion and metastasis within in vitro and in vivo models (69). Another HOX transcript antisense RNA termed HOTAIRMI has recently been implicated in promoting tamoxifen resistance in breast cancer through inhibition of PRC2 activity (100).

Additionally, lncRNA NBAT1 interacts with the EZH2 subunit and may also be dysregulated in breast cancer. NBATI has been identified to be downregulated in breast cancer cells, and has been shown to be associated with metastatic lesions and poor clinical outcomes (101). In vitro, NBAT1 expression 
inhibits migration and invasion through the activation of DKK1, an inhibitor of the WNT signalling pathway (101). The overexpression of NBAT1 downregulates H3K $27 \mathrm{me} 3$ at the $D K K 1$ promoter, while the lack of $N B A T 1$ increases H3K27me3 at the $D K K 1$ promoter, suppressing the expression of this gene (101). Therefore, NBATl has the capacity to negatively regulate $\mathrm{PRC} 2$ activity at the $D K K 1$ promoter, possibly contributing to the pathogenicity of cancer.

A high expression of the lncRNA, LINC00511, has been shown to be associated with a poor prognosis of patients with breast cancer. LINC00511 has been shown to interact with EZH2 and promote recruitment of the PRC2 complex to the promoter of the cell cycle inhibitor $C D K N 1 B$ in estrogen receptor-negative breast cancer (102).

Finally, higher levels of the lncRNA DANCR have been found to be associated with a poor clinical outcome of patients with TNBC (103). DANCR and EZH2 act synergistically to repress the TIMP2/3 and in turn, increase MMP activity (104). The knockdown of DANCR suppresses the invasion and migration of TNBC and prostate cancer cells $(103,104)$.

\section{The miR-200 family and PRC2 activity in breast cancer}

The miR-200 family is a family of small non-coding RNAs consisting of miR-200a, miR-200b, miR-200c. miR-141 and miR-429 that are expressed as two clusters, the miR-200c/141 and miR-200b/200a/429 cluster (105-107). miRNAs are involved in the post-transcriptional regulation of genes and inhibit the translation of target genes (108-110). Research from the authors' laboratory and those of other researchers has indicated that miR-200s are expressed at high levels in luminal breast cancer and luminal breast cancer cell lines; however, their expression is significantly reduced in TNBC and TNBC cell lines (111-117). The miR-200 family negatively regulates the expression of genes involved in EMT, such as TWIST1/2, ZEBI/2 and SNAII/2 (108,118-120). Additionally, SUZ12 may also be an important target of the miR-200 family. SUZ12 translation is directly inhibited by miR-200b $(121,122)$ and thus modifications resulting in the reduced expression of miR-200b in breast cancer cells promote elevated SUZ12 levels and increased H3K27me3 levels by PRC2. Increased PRC2 activity and the elevated expression of EMT-related genes, such as $Z E B I$ ensure that $C D H 1$ transcription is repressed and maintains breast cancer cells in a mesenchymal phenotype $(92,123)$. Of note, miR-200s can also be regulated by PRC2. The miR-200b/a/429 cluster can be silenced through PRC2-mediated histone H3K27me3 modification (124,125). Therefore, feedback loops between miR-200 expression and PRC2 activity may exist in cells.

\section{Therapeutics targeting PRC2 activity in cancers}

PRC2 has been identified as a potential target for the treatment of breast cancer. DZNep can effectively reactivate genes that have been silenced by PRC2 in breast cancer (85). This drug functions to inhibit the methyl group donor, S-adenosylhomocysteine hydrolase, and results in the degradation of EZH2, leading to a decrease in $\mathrm{H} 3 \mathrm{~K} 27$ di and tri-methylation in the promoters of tumor suppressor genes $(126,127)$. DZNep also appears to promote apoptosis by increasing the expression of apoptosis-related genes, such as FBXO32, TGFBI, IGFBP3 and PPPIR15A $(85,126)$. It should be noted that DZNep is not a specific EZH2 inhibitor and thus, other intracellular targets may also mediate the effects of DZNep (127). More recently, MS1943 (1) has been described as a EZH2 selective degrader that is cytotoxic to multiple TNBC cell lines in vitro and in xenograft models (128).

Tazemetostat is an EZH2 inhibitor which functions competitively to inhibit the co-factor, S-adenosyl-L-methionine (SAM), an essential component for EZH2 activity $(129,130)$. Tazemetostat recently gained FDA approval for epithelial sarcomas and clinical trials are currently underway in other types of cancer (131). Other EZH2 inhibitors that target SAM are in early-stage clinical trials, including GSK2816126 and CPI1205 (129) (NCT02082977, NCT02395601, NCT03525795 and NCT03480646).

In addition to targeting the EZH2 subunit of the PRC2 complex, other PRC2 components are also being investigated as therapeutic targets. The EED-EZH2 interaction is critical for EZH2 function and stabilized alpha-helix of EZH2 (SAH-EZH2) peptides have been developed to disrupt the EED-EZH2 interaction, which results in decreased H3K27me3 levels and the degradation of EZH2 (132).

As research uncovers the mechanisms that regulate $\mathrm{H} 3 \mathrm{~K} 27 \mathrm{me} 3$, additional targets outside of the core PRC2 proteins have been identified as possible targets. As mentioned previously, the long non-coding RNA HOTAIR has been observed to recruit PRC2 to target genes (68). The small molecule AC1Q3QWB (AQB) has been identified to selectively disrupt the interaction of HOTAIR with EZH2 during PRC2 recruitment, resulting in elevated levels of HOTAIR target genes such as APC2 (133). Elevated APC2 levels result in the degradation of $\beta$-catenin and the suppression of pro-tumorigenic Wnt/ $\beta$-catenin signaling (133). Other research has aimed to disrupt HOTAIR-EZH2 interaction using peptide nucleic acids (PNAs) that bind to single-stranded regions of HOTAIR (134). Treatment with PNAs has been shown to result in less invasion, reduced tumor formation and increased chemosensitivity in breast cancer cells, as well as ovarian cancer cells (134). Another long non-coding RNA, named DANCR has also been targeted. The nanoparticle-mediated RNA inhibition of DANCR has been shown to knockdown DANCR $80-90 \%$ in cells up to 7 days (135). This administration at a cellular level has been shown to be associated with the downregulation of PRC2 methyltransferase activity at $\mathrm{H} 3 \mathrm{~K} 27 \mathrm{me} 3$, as well as the reduced Wnt/EMT signaling, migration and proliferation of TNBC cells (135).

Therapies designed to target PRC2 may enhance the efficacy of existing therapeutic strategies. For example, PRC2 decreases accessibility to regions of the DNA through chromatin compaction. Chromatin compaction can decrease the sensitivity of cancer cells to chemotherapeutic agents, such as anthracycline (136). In addition, the use of EZH2 inhibitors to decrease global $\mathrm{H} 3 \mathrm{~K} 27 \mathrm{me} 3$ may enhance the efficacy of monoclonal antibodies targeting HER2 (137). De novo resistance in patients has been associated with elevated levels of global H3K27me3 levels in HER2 ${ }^{+}$breast cancer and the administration of EZH2 inhibitor GSK126 in combination with an anti-ErbB2 monoclonal antibody has been shown to significantly suppress tumor growth in an orthotopic mouse tumor model (137). 


\section{Conclusion}

In summary, increased global levels of H3K27me3 can be associated with breast cancer progression, including proliferation, invasion, metastasis, evading apoptosis and EMT. This modification involves the dysregulation of the PRC2 multi-subunit protein which, as stated, may occur through mechanisms involving altered levels of the miR-200 family or lncRNAs. Finally, recent studies utilizing the overexpression of PRC2 as a possible mechanism of pathogenicity have seen some promise in targeting this protein complex. Advancing the understanding of this complex and its potential role in tumorigenicity may provide novel breast cancer therapies.

\section{Acknowledgements}

Not applicable.

\section{Funding}

The present study was funded by a project grant from the Canadian Institutes of Health Research (CIHR, PJT-162218) awarded to RAM.

\section{Availability of data and materials}

Not applicable.

\section{Authors' contributions}

CJM wrote the manuscript and RAM edited the manuscript. Both authors have read and approved the final manuscript.

\section{Ethics approval and consent to participate}

Not applicable.

\section{Patient consent for publication}

Not applicable.

\section{Competing interests}

The authors declare that they have no competing interests.

\section{References}

1. Kim JM, Kim K, Punj V, Liang G, Ulmer TS, Lu W and An W: Linker histone H1. 2 establishes chromatin compaction and gene silencing through recognition of H3K27me3. Sci Rep 5: 16714 , 2015.

2. Cao R, Wang L, Wang H, Xia L, Erdjument-Bromage H, Tempst P, Jones RS and Zhang Y: Role of histone H3 lysine 27 methylation in Polycomb-group silencing. Science 298: 1039-1043, 2002.

3. Czermin B, Melfi R, McCabe D, Seitz V, Imhof A and Pirrotta V: Drosophila enhancer of Zeste/ESC complexes have a histone $\mathrm{H} 3$ methyltransferase activity that marks chromosomal Polycomb sites. Cell 111: 185-196, 2002.

4. Ferrari KJ, Scelfo A, Jammula S, Cuomo A, Barozzi I, Stützer A, Fischle W, Bonaldi T and Pasini D: Polycomb-dependent $\mathrm{H} 3 \mathrm{~K} 27 \mathrm{me} 1$ and $\mathrm{H} 3 \mathrm{~K} 27 \mathrm{me} 2$ regulate active transcription and enhancer fidelity. Mol Cell 53: 49-62, 2014.
5. Kuzmichev A, Nishioka K, Erdjument-Bromage H, Tempst P and Reinberg D: Histone methyltransferase activity associated with a human multiprotein complex containing the Enhancer of Zeste protein. Genes Dev 16: 2893-2905, 2002.

6. Laugesen A, Højfeldt JW and Helin K: Molecular mechanisms directing $\mathrm{PRC} 2$ recruitment and $\mathrm{H} 3 \mathrm{~K} 27$ methylation. Mol Cell 74: 8-18, 2019.

7. Levine SS, Weiss A, Erdjument-Bromage H, Shao Z, Tempst P and Kingston RE: The core of the polycomb repressive complex is compositionally and functionally conserved in flies and humans. Mol Cell Biol 22: 6070-6078, 2002.

8. Lewis EB: A gene complex controlling segmentation in Drosophila. In: Genes, development and cancer. Springer, pp205-217, 1978

9. Margueron R and Reinberg D: The Polycomb complex PRC2 and its mark in life. Nature 469: 343-349, 2011.

10. Rajasekhar VK and Begemann M: Concise review: Roles of polycomb group proteins in development and disease: A stem cell perspective. Stem Cells 25: 2498-2510, 2007.

11. Kasinath V, Faini M, Poepsel S, Reif D, Feng XA, Stjepanovic G, Aebersold R and Nogales E: Structures of human PRC2 with its cofactors AEBP2 and JARID2. Science 359: 940-944, 2018.

12. Hauri S, Comoglio F, Seimiya M, Gerstung M, Glatter T, Hansen K, Aebersold R, Paro R, Gstaiger M and Beisel C: A high-density map for navigating the human polycomb complexome. Cell Rep 17: 583-595, 2016.

13. Kim $\mathrm{H}$, Kang $\mathrm{K}$ and $\mathrm{Kim} \mathrm{J}$ : AEBP2 as a potential targeting protein for Polycomb Repression Complex PRC2. Nucleic Acids Res 37: 2940-2950, 2009.

14. Li G, Margueron R, Ku M, Chambon P, Bernstein BE and Reinberg D: Jarid2 and PRC2, partners in regulating gene expression. Genes Dev 24: 368-380, 2010

15. Peng JC, Valouev A, Swigut T, Zhang J, Zhao Y, Sidow A and Wysocka J: Jarid2/Jumonji coordinates control of PRC2 enzymatic activity and target gene occupancy in pluripotent cells. Cell 139: 1290-1302, 2009.

16. Cao R and Zhang YI: SUZ12 is required for both the histone methyltransferase activity and the silencing function of the EED-EZH2 complex. Mol Cell 15: 57-67, 2004.

17. Denisenko O, Shnyreva M, Suzuki H and Bomsztyk K: Point mutations in the WD40 domain of Eed block its interaction with Ezh2. Mol Cell Biol 18: 5634-5642, 1998.

18. Pasini D, Bracken AP, Jensen MR, Denchi EL and Helin K Suz12 is essential for mouse development and for EZH2 histone methyltransferase activity. EMBO J 23: 4061-4071, 2004.

19. Moritz LE and Trievel RC: Structure, mechanism, and regulation of polycomb-repressive complex 2. J Biol Chem 293: 13805-13814, 2018

20. Varambally S, Dhanasekaran SM, Zhou M, Barrette TR, Kumar-Sinha C, Sanda MG, Ghosh D, Pienta KJ, Sewalt RG, Otte AP, et al: The polycomb group protein EZH2 is involved in progression of prostate cancer. Nature 419: 624-629, 2002.

21. Jiao L and Liu X: Structural basis of histone H3K27 trimethylation by an active polycomb repressive complex 2 . Science 350 : aac4383, 2015.

22. Margueron R, Justin N, Ohno K, Sharpe ML, Son J, Drury WJ III, Voigt P, Martin SR, Taylor WR, De Marco V, et al: Role of the polycomb protein EED in the propagation of repressive histone marks. Nature 461: 762-767, 2009.

23. Nekrasov M, Wild B and Müller J: Nucleosome binding and histone methyltransferase activity of Drosophila PRC2. EMBO Rep 6: 348-353, 2005

24. Han Z, Xing X, Hu M, Zhang Y, Liu P and Chai J: Structural basis of EZH2 recognition by EED. Structure 15: 1306-1315, 2007.

25. Montgomery ND, Yee D, Chen A, Kalantry S, Chamberlain SJ, Otte AP and Magnuson T: The murine polycomb group protein Eed is required for global histone H3 lysine-27 methylation. Curr Biol 15: 942-947, 2005.

26. Pasini D, Bracken AP, Hansen JB, Capillo M and Helin K: The polycomb group protein Suz12 is required for embryonic stem cell differentiation. Mol Cell Biol 27: 3769-3779, 2007.

27. Højfeldt JW, Laugesen A, Willumsen BM, Damhofer H, Hedehus L, Tvardovskiy A, Mohammad F, Jensen ON and Helin K: Accurate H3K27 methylation can be established de novo by SUZ12-directed PRC2. Nat Struct Mol biol 25: 225-232, 2018.

28. Kleer CG, Cao Q, Varambally S, Shen R, Ota I, Tomlins SA, Ghosh D, Sewalt RG, Otte AP, Hayes DF, et al: EZH2 is a marker of aggressive breast cancer and promotes neoplastic transformation of breast epithelial cells. Proc Natl Acad Sci USA 100: 11606-11611, 2003 
29. Margueron R, Li G, Sarma K, Blais A, Zavadil J, Woodcock CL, Dynlacht BD and Reinberg D: Ezh1 and Ezh2 maintain repressive chromatin through different mechanisms. Mol Cell 32: 503-518, 2008.

30. Lee CH, Holder M, Grau D, Saldaña-Meyer R, Yu JR, Ganai RA, Zhang J, Wang M, LeRoy G, Dobenecker MW, et al: Distinct stimulatory mechanisms regulate the catalytic activity of polycomb repressive complex 2. Mol Cell 70: 435-448.e5, 2018.

31. Chen S, Jiao L, Shubbar M, Yang X and Liu X: Unique structural platforms of Suz12 dictate distinct classes of PRC2 for chromatin binding. Mol Cell 69: 840-852.e5, 2018.

32. Schmitges FW, Prusty AB, Faty M, Stützer A, Lingaraju GM, Aiwazian J, Sack R, Hess D, Li L, Zhou S, et al: Histone methylation by PRC 2 is inhibited by active chromatin marks. Mol Cell 42: 330-341, 2011.

33. Pasini D, Cloos PAC, Walfridsson J, Olsson L, Bukowski JP Johansen JV, Bak M, Tommerup N, Rappsilber J and Helin K JARID2 regulates binding of the Polycomb repressive complex 2 to target genes in ES cells. Nature 464: 306-310, 2010

34. Murzina NV, Pei XY, Zhang W, Sparkes M, Vicente-Garcia J, Pratap JV, McLaughlin SH, Ben-Shahar TR, Verreault A, Luisi BF and Laue ED: Structural basis for the recognition of histone $\mathrm{H} 4$ by the histone-chaperone RbAp46. Structure 16: 1077-1085, 2008.

35. Zhang W, Tyl M, Ward R, Sobott F, Maman J, Murthy AS, Watson AA, Fedorov O, Bowman A, Owen-Hughes T, et al: Structural plasticity of histones $\mathrm{H} 3-\mathrm{H} 4$ facilitates their allosteric exchange between RbAp48 and ASF1. Nat Struct Mol Biol 20: 29-35, 2013.

36. Kouznetsova VL, Tchekanov A, Li X, Yan X and Tsigelny IF: Polycomb repressive 2 complex-molecular mechanisms of function. Protein Sci 28: 1387-1399, 2019.

37. Landeira D, Sauer S, Poot R, Dvorkina M, Mazzarella L, Jørgensen HF, Pereira CF, Leleu M, Piccolo FM, Spivakov M, et al: Jarid2 is a PRC2 component in embryonic stem cells required for multi-lineage differentiation and recruitment of PRC1 and RNA Polymerase II to developmental regulators. Nat Cell Biol 12: 618-624, 2010

38. Son J, Shen SS, Margueron R and Reinberg D: Nucleosomebinding activities within JARID2 and EZH1 regulate the function of PRC2 on chromatin. Genes Dev 27: 2663-2677, 2013.

39. Cooper S, Grijzenhout A, Underwood E, Ancelin K, Zhang T, Nesterova TB, Anil-Kirmizitas B, Bassett A, Kooistra SM, Agger K, et al: Jarid2 binds mono-ubiquitylated H2A lysine 119 to mediate crosstalk between Polycomb complexes PRC1 and PRC2. Nat Commun 7: 13661, 2016.

40. Endoh M, Endo TA, Endoh T, Isono K, Sharif J, Ohara O, Toyoda T, Ito T, Eskeland R, Bickmore WA, et al: Histone H2A mono-ubiquitination is a crucial step to mediate PRC1-dependent repression of developmental genes to maintain ES cell identity. PLoS Genet 8: e1002774, 2012.

41. Kalb R, Latwiel S, Baymaz HI, Jansen PW, Müller CW, Vermeulen M and Müller J: Histone H2A monoubiquitination promotes histone H3 methylation in Polycomb repression. Nat Struct Mol Biol 21: 569-571, 2014

42. Shen X, Kim W, Fujiwara Y, Simon MD, Liu Y, Mysliwiec MR, Yuan GC, Lee Y and Orkin SH: Jumonji modulates polycomb activity and self-renewal versus differentiation of stem cells Cell 139: 1303-1314, 2009.

43. Ballaré C, Lange M, Lapinaite A, Martin GM, Morey L, Pascual G, Liefke R, Simon B, Shi Y, Gozani O, et al: Phf19 links methylated Lys 36 of histone $\mathrm{H} 3$ to regulation of Polycomb activity. Nat Struct Mol Biol 19: 1257-1265, 2012.

44. Musselman CA, Avvakumov N, Watanabe R, Abraham CG, Lalonde ME, Hong Z, Allen C, Roy S, Nuñez JK, Nickoloff J, et al: Molecular basis for $\mathrm{H} 3 \mathrm{~K} 36 \mathrm{me} 3$ recognition by the Tudor domain of PHF1. Nat Struct Mol Biol 19: 1266-1272, 2012.

45. Boulay G, Rosnoblet C, Guérardel C, Angrand PO and Leprince D: Functional characterization of human Polycomb-like 3 isoforms identifies them as components of distinct EZH2 protein complexes. Biochem J 434: 333-342, 2011.

46. Li H, Liefke R, Jiang J, Kurland JV, Tian W, Deng P, Zhang W, He Q, Patel DJ, Bulyk ML, et al: Polycomb-like proteins link the PRC2 complex to CpG islands. Nature 549: 287-291, 2017.

47. Hou Y, Liu W, Yi X, Yang Y, Su D, Huang W, Yu H, Teng X, Yang Y, Feng W, et al: PHF20L1 as a H3K27me2 reader coordinates with transcriptional repressors to promote breast tumorigenesis. Sci Adv 6: eaaz0356, 2020.
48. Perino M, van Mierlo G, Karemaker ID, van Genesen S, Vermeulen M, Marks H, vanHeeringen SJ and Veenstra GJC: MTF2 recruits polycomb repressive Complex 2 by helical-shape-selective DNA binding. Nat Genet 50: 1002-1010, 2018

49. Hansen KH, Bracken AP, Pasini D, Dietrich N, Gehani SS, Monrad A, Rappsilber J, Lerdrup M and Helin K: A model for transmission of the H3K27me3 epigenetic mark. Nat Cell Biol 10: 1291-1300, 2008.

50. Oksuz O, Narendra V, Lee CH, Descostes N, LeRoy G, Raviram R, Blumenberg L, Karch K, Rocha PP, Garcia BA, et al: Capturing the onset of PRC2-mediated repressive domain formation. Mol Cell 70: 1149-1162.e5, 2018.

51. Boyer LA, Plath K, Zeitlinger J, Brambrink T, Medeiros LA, Lee TI, Levine SS, Wernig M, Tajonar A, Ray MK, et al: Polycomb complexes repress developmental regulators in murine embryonic stem cells. Nature 441: 349-353, 2006.

52. Bracken AP, Dietrich N, Pasini D, Hansen KH and Helin K: Genome-wide mapping of Polycomb target genes unravels their roles in cell fate transitions. Genes Dev 20: 1123-1136, 2006.

53. Lee TI, Jenner RG, Boyer LA, Guenther MG, Levine SS, Kumar RM, Chevalier B, Johnstone SE, Cole MF, Isono K, et al: Control of developmental regulators by Polycomb in human embryonic stem cells. Cell 125: 301-313, 2006.

54. Schwartz YB, Kahn TG, Nix DA, Li XY, Bourgon R, Biggin M and Pirrotta V: Genome-wide analysis of polycomb targets in drosophila melanogaster. Nat Genet 38: 700-705, 2006.

55. Ren C, Morohashi K, Plotnikov AN, Jakoncic J, Smith SG, Li J, Zeng L, Rodriguez Y, Stojanoff V, Walsh M and Zhou MM: Small-molecule modulators of methyl-lysine binding for the CBX7 chromodomain. Chem Biol 22: 161-168, 2015.

56. Zhen CY, Tatavosian R, Huynh TN, Duc HN, Das R, Kokotovic M, Grimm JB, Lavis LD, Lee J, Mejia FJ, et al: Live-cell single-molecule tracking reveals co-recognition of $\mathrm{H} 3 \mathrm{~K} 27 \mathrm{me} 3$ and DNA targets polycomb Cbx7-PRC1 to chromatin. Elife 5: e17667, 2016.

57. Blackledge NP, Farcas AM, Kondo T, King HW, McGouran JF, Hanssen LLP, Ito S, Cooper S, Kondo K, Koseki Y, et al: Variant PRC1 complex-dependent H2A ubiquitylation drives PRC2 recruitment and polycomb domain formation. Cell 157: 1445-1459, 2014.

58. Cooper S, Dienstbier M, Hassan R, Schermelleh L, Sharif J, Blackledge NP, De Marco V, Elderkin S, Koseki H, et al: Targeting polycomb to pericentric heterochromatin in embryonic stem cells reveals a role for $\mathrm{H} 2 \mathrm{AK} 119 \mathrm{u} 1$ in PRC2 recruitment. Cell Rep 7: 1456-1470, 2014.

59. Bhatnagar S, Gazin C, Chamberlain L, Ou J, Zhu X, Tushir JS Virbasius CM, Lin L, Zhu LJ, Wajapeyee N and Green MR: TRIM37 is a new histone H2A ubiquitin ligase and breast cancer oncoprotein. Nature 516: 116-120, 2014.

60. Sanulli S, Justin N, Teissandier A, Ancelin K, Portoso M, Caron M, Michaud A, Lombard B, da Rocha ST, Offer J, et al: Jarid2 methylation via the PRC2 complex regulates H3K27me3 deposition during cell differentiation. Mol Cell 57: 769-783, 2015.

61. Riising EM, Comet I, Leblanc B, Wu X, Johansen JV and Helin K: Gene silencing triggers polycomb repressive complex 2 recruitment to $\mathrm{CpG}$ islands genome wide. Mol Cell 55: 347-360, 2014.

62. Kahn TG, Dorafshan E, Schultheis D, Zare A, Stenberg P, Reim I, Pirrotta V and Schwartz YB: Interdependence of PRC1 and PRC2 for recruitment to Polycomb Response Elements. Nucleic Acids Res 44: 10132-10149, 2016.

63. Bauer M, Trupke J and Ringrose L: The quest for mammalian Polycomb response elements: Are we there yet? Chromosoma 125: 471-496, 2016

64. Mikkelsen TS, Ku M, Jaffe DB, Issac B, Lieberman E, Giannoukos G, Alvarez P, Brockman W, Kim TK, Koche RP, et al: Genome-wide maps of chromatin state in pluripotent and lineage-committed cells. Nature 448: 553-560, 2007.

65. Brien GL, Gambero G, O'connell DJ, Jerman E, Turner SA, Egan CM, Dunne EJ, Jurgens MC, Wynne K, Piao L, et al: Polycomb PHF19 binds H3K36me 3 and recruits PRC 2 and demethylase NO66 to embryonic stem cell genes during differentiation. Nat Struct Mol Biol 19: 1273-1281, 2012.

66. Cai L, Rothbart SB, Lu R, Xu B, Chen WY, Tripathy A, Rockowitz S, Zheng D, Patel DJ, Allis CD, et al: An H3K36 methylation-engaging Tudor motif of polycomb-like proteins mediates PRC2 complex targeting. Mol Cell 49: 571-582, 2013.

67. Rinn JL, Kertesz M, Wang JK, Squazzo SL, Xu X, Brugmann SA, Goodnough LH, Helms JA, Farnham PJ, Segal E and Chang HY: Functional demarcation of active and silent chromatin domains in human HOX loci by noncoding RNAs. Cell 129: 1311-1323, 2007. 
68. Tsai MC, Manor O, Wan Y, Mosammaparast N, Wang JK, Lan F, Shi Y, Segal E and Chang HY: Long noncoding RNA as modular scaffold of histone modification complexes. Science 329: 689-693, 2010

69. Gupta RA, Shah N, Wang KC, Kim J, Horlings HM, Wong DJ, Tsai MC, Hung T, Argani P, Rinn JL, et al: Long non-coding RNA HOTAIR reprograms chromatin state to promote cancer metastasis. Nature 464: 1071-1076, 2010.

70. Zhou X, Ren Y, Zhang J, Zhang C, Zhang K, Han L, Kong L, Wei J, Chen L, Yang J, et al: HOTAIR is a therapeutic target in glioblastoma. Oncotarget 6: 8353-8365, 2015.

71. Bracken AP, Pasini D, Capra M, Prosperini E, Colli E and Helin K: EZH2 is downstream of the pRB-E2F pathway, essential for proliferation and amplified in cancer. EMBO J 22: 5323-5335, 2003.

72. Bachmann IM, Halvorsen OJ, Collett K, Stefansson IM, Straume O, Haukaas SA, Salvesen HB, Otte AP and Akslen LA EZH2 expression is associated with high proliferation rate and aggressive tumor subgroups in cutaneous melanoma and cancers of the endometrium, prostate, and breast. J Clin Oncol 24: 268-273, 2006.

73. Derfoul A, Juan AH, Difilippantonio MJ, Palanisamy N, Ried T and Sartorelli V: Decreased microRNA-214 levels in breast cancer cells coincides with increased cell proliferation, invasion and accumulation of the Polycomb Ezh2 methyltransferase. Carcinogenesis 32: 1607-1614, 2011.

74. Kong X, Chen L, Jiao L, Jiang X, Lian F, Lu J, Zhu K, Du D Liu J, Ding $\mathrm{H}$, et al: Astemizole arrests the proliferation of cancer cells by disrupting the EZH2-EED interaction of polycomb repressive complex 2. J Med Chem 57: 9512-9521, 2014.

75. Yu H, Simons DL, Segall I, Carcamo-Cavazos V, Schwartz EJ, Yan N, Zuckerman NS, Dirbas FM, Johnson DL, Holmes SP and Lee PP: PRC2/EED-EZH2 complex is up-regulated in breast cancer lymph node metastasis compared to primary tumor and correlates with tumor proliferation in situ. PLoS One 7: e51239, 2012

76. Curran S and Murray GI: Matrix metalloproteinases in tumour invasion and metastasis. J Pathol 189: 300-308, 1999.

77. Merdad A, Karim S, Schulten HJ, Dallol A, Buhmeida A, Al-Thubaity F, Gari MA, Chaudhary AG, Abuzenadah AM and Al-Qahtani MH: Expression of matrix metalloproteinases (MMPs) in primary human breast cancer: MMP-9 as a potential biomarker for cancer invasion and metastasis. Anticancer Res 34: 1355-1366, 2014

78. Chien YC, Liu LC, Ye HY, Wu JY and Yu YL: EZH2 promotes migration and invasion of triple-negative breast cancer cells via regulating TIMP2-MMP-2/-9 pathway. Am J Cancer Res 8: 422-434, 2018.

79. Shin YJ and Kim JH: The role of EZH2 in the regulation of the activity of matrix metalloproteinases in prostate cancer cells. PLoS One 7: e30393, 2012.

80. Yi X, Guo J, Guo J, Sun S, Yang P, Wang J, Li Y, Xie L, Cai J and Wang Z: EZH2-mediated epigenetic silencing of TIMP2 promotes ovarian cancer migration and invasion. Sci Rep 7: 3568, 2017.

81. Wang T, Mao B, Cheng C, Zou Z, Gao J, Yang Y, Lei T, Qi X, Yuan Z, Xu W and Lu Z: YAP promotes breast cancer metastasis by repressing growth differentiation factor-15. Biochim Biophys Acta Mol Basis Dis 1864: 1744-1753, 2018.

82. Overholtzer M, Zhang J, Smolen GA, Muir B, Li W, Sgroi DC Deng CX, Brugge JS and Haber DA: Transforming properties of YAP, a candidate oncogene on the chromosome 11q22 amplicon. Proc Natl Acad Sci USA 103: 12405-12410, 2006.

83. Song Q, Mao B, Cheng J, Gao Y, Jiang K, Chen J, Yuan Z and Meng S: YAP enhances autophagic flux to promote breast cancer cell survival in response to nutrient deprivation. PLoS One 10: e0120790, 2015.

84. Yuan M, Tomlinson V, Lara R, Holliday D, Chelala C, Harada T, Gangeswaran R, Manson-Bishop C, Smith P, Danovi SA, et al: Yes-associated protein (YAP) functions as a tumor suppressor in breast. Cell Death Differ 15: 1752-1759, 2008.

85. Tan J, Yang X, Zhuang L, Jiang X, Chen W, Lee PL, Karuturi RK, Tan PB, Liu ET and Yu Q: Pharmacologic disruption of Polycomb-repressive complex 2-mediated gene repression selectively induces apoptosis in cancer cells. Genes Dev 21: 1050-1063, 2007.

86. Wu Z, Lee S, Qiao Y, Li Z, Lee PL, Lee YJ, Jiang X, Tan J, Aau M, Lim CZ and Yu Q: Polycomb protein EZH2 regulates cancer cell fate decision in response to DNA damage. Cell Death Differ 18: 1771-1779, 2011.
87. Wu ZL, Zheng SS, Li ZM, Qiao YY, Aau MY and Yu Q: Polycomb protein EZH2 regulates E2F1-dependent apoptosis through epigenetically modulating Bim expression. Cell Death Differ 17: 801-810, 2010.

88. Zhang B, Liu XX, He JR, Zhou CX, Guo M, He M, Li MF, Chen GQ and Zhao Q: Pathologically decreased miR-26a antagonizes apoptosis and facilitates carcinogenesis by targeting MTDH and EZH2 in breast cancer. Carcinogenesis 32: 2-9, 2011.

89. Zhang Q, Padi SKR, Tindall DJ and Guo B: Polycomb protein EZH2 suppresses apoptosis by silencing the proapoptotic miR-31. Cell Death Dis 5: e1486, 2014.

90. Pietersen AM, Horlings HM, Hauptmann M, Langerød A, Ajouaou A, Cornelissen-Steijger P, Wessels LF, Jonkers J, van de Vijver MJ and van Lohuizen M: EZH2 and BMI1 inversely correlate with prognosis and TP53 mutation in breast cancer. Breast Cancer Res 10: R109, 2008.

91. Onder TT, Gupta PB, Mani SA, Yang J, Lander ES and Weinberg RA: Loss of E-cadherin promotes metastasis via multiple downstream transcriptional pathways. Cancer Res 68: 3645-3654, 2008

92. Lester RD, Jo M, Montel V, Takimoto S and Gonias SL: uPAR induces epithelial-mesenchymal transition in hypoxic breast cancer cells. J Cell Biol 178: 425-436, 2007.

93. Schmalhofer O, Brabletz S and Brabletz T: E-cadherin, $\beta$-catenin, and ZEB1 in malignant progression of cancer. Cancer and Metastasis Rev 28: 151-166, 2009.

94. Herranz N, Pasini D, Díaz VM, Francí C, Gutierrez A, Dave N, Escrivà M, Hernandez-Muñoz I, Di Croce L, Helin K, et al: Polycomb complex 2 is required for E-cadherin repression by the Snail1 transcription factor. Mol Cell Biol 28: 4772-4781, 2008.

95. Anwar T, Arellano-Garcia C, Ropa J, Chen YC, Kim HS, Yoon E, Grigsby S, Basrur V, Nesvizhskii AI, Muntean A, et al: p38-mediated phosphorylation at T367 induces EZH2 cytoplasmic localization to promote breast cancer metastasis. Nat Commun 9: 2801, 2018.

96. Li J, Xi Y, Li W, McCarthy RL, Stratton SA, Zou W, Li W, Dent SY, Jain AK and Barton MC: TRIM28 interacts with EZH2 and SWI/SNF to activate genes that promote mammosphere formation. Oncogene 36: 2991-3001, 2017.

97. Mahara S, Lee PL, Feng M, Tergaonkar V, Chng WJ and Yu Q: HIFI- $\alpha$ activation underlies a functional switch in the paradoxical role of Ezh2/PRC2 in breast cancer. Proc Natl Acad Sci USA 113: E3735-E3744, 2016.

98. Chisholm KM, Wan Y, Li R, Montgomery KD, Chang HY and West RB: Detection of long non-coding RNA in archival tissue: Correlation with polycomb protein expression in primary and metastatic breast carcinoma. PLoS One 7: e47998, 2012.

99. Sørensen KP, Thomassen M, Tan Q, Bak M, Cold S, Burton M, Larsen MJ and Kruse TA: Long non-coding RNA HOTAIR is an independent prognostic marker of metastasis in estrogen receptor-positive primary breast cancer. Br Cancer Res Treat 142: 529-536, 2013.

100. Kim CY, Oh JH, Lee JY and Kim MH: The LncRNA HOTAIRM1 promotes tamoxifen resistance by mediating HOXA1 expression in ER+ Breast Cancer Cells. J Cancer 11: 3416-3423, 2020.

101. Hu P, Chu J, Wu Y, Sun L, Lv X, Zhu Y, Li J, Guo Q, Gong C, Liu B and Su S: NBAT1 suppresses breast cancer metastasis by regulating DKK1 via PRC2. Oncotarget 6: 32410-32425, 2015.

102. Zhang J, Sui S, Wu H, Zhang J, Zhang X, Xu S and Pang D: The transcriptional landscape of lncRNAs reveals the oncogenic function of LINC00511 in ER-negative breast cancer. Cell Death Dis 10: 599, 2019.

103. Sha S, Yuan D, Liu Y, Han B and Zhong N: Targeting long non-coding RNA DANCR inhibits triple negative breast cancer progression. Biol Open 6: 1310-1316, 2017.

104. Jia J, Li F, Tang XS, Xu S, Gao Y, Shi Q, Guo W, Wang X, He D and Guo P: Long noncoding RNA DANCR promotes invasion of prostate cancer through epigenetically silencing expression of TIMP2/3. Oncotarget 7: 37868-37881, 2016.

105. Saini HK, Enright AJ and Griffiths-Jones S: Annotation of mammalian primary microRNAs. BMC Genomics 9: 564, 2008.

106. Park SM, Gaur AB, Lengyel E and Peter ME: The miR-200 family determines the epithelial phenotype of cancer cells by targeting the E-cadherin repressors ZEB1 and ZEB2. Genes Dev 22: 894-907, 2008.

107. Hill L, Browne G and Tulchinsky E: ZEB/miR-200 feedback loop: At the crossroads of signal transduction in cancer. Int J Cancer 132: 745-754, 2013. 
108. Ambros V: The functions of animal microRNAs. Nature 431: 350-355, 2004.

109. Mei J, Hao L, Wang H, Xu R, Liu Y, Zhu Y and Liu C: Systematic characterization of non-coding RNAs in triple-negative breast cancer. Cell Prolif 53: e12801, 2020.

110. Bartel DP: MicroRNAs: Genomics, biogenesis, mechanism, and function. Cell 116: 281-297, 2004.

111. Jones R, Watson K, Bruce A, Nersesian S, Kitz J and Moorehead R: $\mathrm{Re}$-expression of miR-200c suppresses proliferation, colony formation and in vivo tumor growth of murine Claudin-low mammary tumor cells. Oncotarget 8: 23727-23749, 2017.

112. Watson KL, Jones RA, Bruce A and Moorehead RA: The miR-200b/200a/429 cluster prevents metastasis and induces dormancy in a murine claudin-low mammary tumor cell line. Exp Cell Res 369: 17-26, 2018.

113. Bockmeyer CL, Christgen M, Müller M, Fischer S, Ahrens P, Länger F, Kreipe H and Lehmann U: MicroRNA profiles of healthy basal and luminal mammary epithelial cells are distinct and reflected in different breast cancer subtypes. Breast Cancer ResTreat 130: 735-745, 2011.

114. Cochrane DR, Cittelly DM, Howe EN, Spoelstra NS, McKinsey EL, LaPara K, Elias A, Yee D and Richer JK: MicroRNAs link estrogen receptor alpha status and Dicer levels in breast cancer. Horm Cancer 1: 306-319, 2010.

115. Korpal M, Lee ES, Hu G and Kang Y: The miR-200 family inhibits epithelial-mesenchymal transition and cancer cell migration by direct targeting of E-cadherin transcriptional repressors ZEB1 and ZEB2. J Biol Chem 283: 14910-14914, 2008.

116. Mekala JR, Naushad SM, Ponnusamy L, Arivazhagan G, Sakthiprasad V and Pal-Bhadra M: Epigenetic regulation of miR-200 as the potential strategy for the therapy against triple-negative breast cancer. Gene 641: 248-258, 2018

117. Humphries B, Wang Z, Oom AL, Fisher T, Tan D, Cui Y, Jiang Y and Yang C: MicroRNA-200b targets protein kinase Calpha and suppresses triple-negative breast cancer metastasis. Carcinogenesis 35: 2254-2263, 2014.

118. Bracken CP, Gregory PA, Kolesnikoff N, Bert AG, Wang J, Shannon MF and Goodall GJ: A double-negative feedback loop between ZEB1-SIP1 and the microRNA-200 family regulates epithelial-mesenchymal transition. Cancer Res 68: 7846-7854, 2008.

119. Howe EN, Cochrane DR and Richer JK: The miR-200 and miR-221/222 microRNA families: Opposing effects on epithelial identity. J Mammary Gland Biol Neoplasia 17: 65-77, 2012.

120. Radisky DC: miR-200c at the nexus of epithelial-mesenchyma transition, resistance to apoptosis, and the breast cancer stem cell phenotype. Breast Cancer Res 13: 110, 2011.

121. Iliopoulos D, Lindahl-Allen M, Polytarchou C, Hirsch HA, Tsichlis PN and Struhl K: Loss of miR-200 inhibition of Suz12 leads to polycomb-mediated repression required for the formation and maintenance of cancer stem cells. Mol Cell 39: 761-772, 2010.

122. Peng F, Jiang J, Yu Y, Tian R, Guo X, Li X, Shen M, Xu M, Zhu F, Shi C, et al: Direct targeting of SUZ12/ROCK2 by $\mathrm{miR}-200 \mathrm{~b} / \mathrm{c}$ inhibits cholangiocarcinoma tumourigenesis and metastasis. Br J Cancer 109: 3092-3104, 2013.

123. Siitonen SM, Kononen JT, Helin HJ, Rantala IS, Holli KA and Isola JJ: Reduced E-cadherin expression is associated with invasiveness and unfavorable prognosis in breast cancer. Am J Clin Pathol 105: 394-402, 1996.
124.Lim YY, Wright JA, Attema JL, Gregory PA, Bert AG, Smith E, Thomas D, Lopez AF, Drew PA, Khew-Goodall Y and Goodall GJ: Epigenetic modulation of the miR-200 family is associated with transition to a breast cancer stem-cell-like state. J Cell Sci 126: 2256-2266, 2013.

125. Ning X, Shi Z, Liu X, Zhang A, Han L, Jiang K, Kang C and Zhang Q: DNMT1 and EZH2 mediated methylation silences the microRNA-200b/a/429 gene and promotes tumor progression. Cancer Lett 359: 198-205, 2015.

126. Fiskus W, Wang Y, Sreekumar A, Buckley KM, Shi H, Jillella A, Ustun C, Rao R, Fernandez P, Chen J, et al: Combined epigenetic therapy with the histone methyltransferase EZH2 inhibitor 3-deazaneplanocin A and the histone deacetylase inhibitor panobinostat against human AML cells. Blood 114: 2733-2743, 2009.

127. Miranda TB, Cortez CC, Yoo CB, Liang G, Abe M, Kelly TK, Marquez VE and Jones PA: DZNep is a global histone methylation inhibitor that reactivates developmental genes not silenced by DNA methylation. Mol Cancer Ther 8: 1579-1588, 2009.

128. Ma A, Stratikopoulos E, Park KS, Wei J, Martin TC, Yang X, Schwarz M, Leshchenko V, Rialdi A, Dale B, et al: Discovery of a first-in-class EZH2 selective degrader. Nat Chem Biol 16: 214-222, 2020.

129. Gulati N, Béguelin W and Giulino-Roth L: Enhancer of zeste homolog 2 (EZH2) inhibitors. Leuk Lymphoma 59: 1574-1585, 2018.

130. Richart L and Margueron R: Drugging histone methyltransferases in cancer. Curr Opin Chem Biol 56: 51-62, 2020.

131. Hoy SM: Tazemetostat: First approval. Drugs 80: 513-521, 2020.

132. Kim W, Bird GH, Neff T, Guo G, Kerenyi MA, Walensky LD and Orkin SH: Targeted disruption of the EZH2-EED complex inhibits EZH2-dependent cancer. Nat Chem Biol 9: 643-650, 2013.

133. Li Y, Ren Y, Wang Y, Tan Y, Wang Q, Cai J, Zhou J, Yang C, Zhao K, Yi K, et al: A compound AC1Q3QWB selectively disrupts HOTAIR-mediated recruitment of PRC2 and enhances cancer therapy of DZNep. Theranostics 9: 4608-4623, 2019.

134. Özeş AR, Wang Y, Zong X, Fang F, Pilrose J and Nephew KP: Therapeutic targeting using tumor specific peptides inhibits long non-coding RNA HOTAIR activity in ovarian and breast cancer. Sci Rep 7: 894, 2017.

135. Vaidya AM, Sun Z, Ayat N, Schilb A, Liu X, Jiang H, Sun D, Scheidt J, Qian V, He S, et al: Systemic delivery of tumor-targeting siRNA nanoparticles against an oncogenic LncRNA facilitates effective triple-negative breast cancer therapy. Bioconjug Chem 30: 907-919, 2019.

136. Seoane JA, Kirkland JG, Caswell-Jin JL, Crabtree GR and Curtis C: Chromatin regulators mediate anthracycline sensitivity in breast cancer. Nat Med 25: 1721-1727, 2019.

137. Hirukawa A, Singh S, Wang J, Rennhack JP, Swiatnicki M, Sanguin-Gendreau V, Zuo D, Daldoul K, Lavoie C, Park M, et al: Reduction of Global H3K27me $\mathrm{m}^{3}$ Enhances HER2/ErbB2 targeted therapy. Cell Rep 29: 249-257, 2019. International (CC BY-NC-ND 4.0) License. 